\title{
Shock pulse shaping in a small-form factor velocity amplifier
}

\author{
Gerard Kelly ${ }^{\mathrm{a}, *}$, Jeff Punch ${ }^{\mathrm{a}}$, Suresh Goyal ${ }^{\mathrm{b}}$ and Michael Sheehy ${ }^{\mathrm{a}}$ \\ ${ }^{a}$ CTVR, Stokes Institute, University of Limerick, Limerick, Ireland \\ ${ }^{\mathrm{b}}$ Bell Labs Ireland, Alcatel-Lucent, Blanchardstown Industrial Park, Blanchardstown, Dublin, Ireland
}

Received 23 June 2009

\begin{abstract}
This theme of this paper is the design and characterisation of a velocity amplifier (VAMP) machine for high-acceleration shock testing of micro-scale devices. The VAMP applies multiple sequential impacts to amplify velocity through a system of three progressively smaller masses constrained to move in the vertical axis. Repeatable, controlled, mechanical shock pulses are created through the metal-on-metal impact between pulse shaping test rods, which form part of the penultimate and ultimate masses. The objectives are to investigate the controllable parameters that affect the shock pulses induced on collision, namely; striker and incident test rod material; test rod length; pulse shaping mechanisms; and impact velocity.

The optimum VAMP configuration was established as a $60 \mathrm{~mm}$ long titanium striker test rod and a $120 \mathrm{~mm}$ long titanium incident rod. This configuration exhibited an acceleration magnitude and a primary pulse duration range of 5,800-23,400 $\mathrm{g}$ and $28.0-44.0 \mu$ s respectively. It was illustrated that the acceleration spectral content can be manipulated through control of the test rod material and length. This is critical in the context of practical applications, where it is postulated that the acceleration signal can be controlled to effectively excite specific components in a multi-component assembly affixed to the VAMP incident test rod.
\end{abstract}

Keywords: Shock, impact, pulse shape, high-acceleration, velocity amplification, stress wave propagation

\section{Introduction}

Recent technological development has witnessed a continuing trend towards the miniaturisation of electronic devices. As a consequence, application areas for Micro-Electro-Mechanical Systems (MEMS) have expanded into the automotive, aerospace, military and telecommunications sectors. Gad-El-Hak [1] has noted that electronic components such as inductors and tunable capacitors fabricated using MEMS technology offer distinct advantages over their integrated counterparts. However, the reliability engineering of MEMS devices is still in its infancy, particularly with respect to micro-devices deployed in harsh environments that are subject to shock stimuli that may induce stress related failure, such as those analysed by Srikar and Senturia [2]. This is of paramount concern for devices that have applications in high-acceleration environments such as missile control systems. The acceleration pulse shape is a critical aspect of high-acceleration shock testing as clean, consistent pulse shapes are extremely difficult to obtain [3]. State-of-the-art high-acceleration shock test methods include Hopkinson pressure bar (HPB) techniques [4,5], ballistics, rail and air guns, drop testing, and centrifuging. Some of the difficulties with these methods include large size, high cost, safety and repeatability issues. The theme of this paper is an investigation of a velocity amplifier (VAMP) machine for high-acceleration shock testing of micro-scale devices.

The primary objective of this paper is the realisation of a small-scale and cost-effective platform which can provide repeatable high-acceleration pulses, of controllable acceleration magnitude and primary pulse duration. To this end, the VAMP shock testing machine is based on the principle of using multiple, sequential impacts to amplify

\footnotetext{
*Corresponding author. Tel.: +353 61 233619; Fax: +353 61 202393; E-mail: Gerard.Kelly@ul.ie.
} 

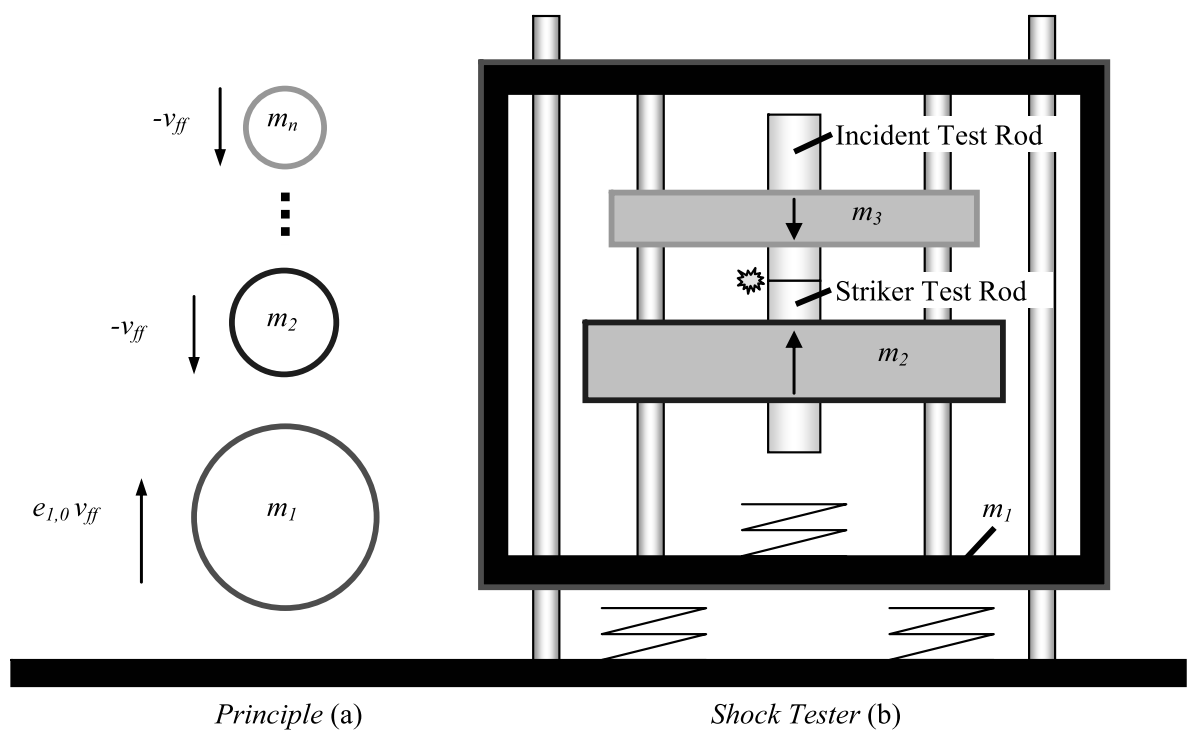

Fig. 1. VAMP principle and a schematic of a VAMP shock tester. denotes impact event.

velocity through a system of progressively smaller masses constrained to move in the vertical axis. An illustrative example of the velocity amplification process is displayed in Fig. 1(a), with a chain of masses $m_{2}-m_{n}$ falling with a free-fall velocity $v_{f f}$, and mass $m_{1}$ rebounds at a velocity dependent on the coefficient of restitution, $e$. The process is explained in detail by Rodgers et al. [6-8]. The VAMP principle represents a promising design for a range of applications such as; launchers (velocity amplification); armour (energy absorption); and enhanced energy harvesters. Figure 1(a) illustrates the principle with an accompanying schematic in Fig. 1(b) demonstrating a realisation of the principle as a shock tester.

The VAMP mechanical shock pulses are created through the metal-on-metal finite collinear rod impact between the striker and incident pulse shaping test rods as illustrated in Fig. 1(b), which is the critical element of operation. The plane-ended cylindrical test rods are partially enclosed within the penultimate, $m_{2}$, and ultimate, $m_{3}$, masses.

This paper investigates VAMP shock pulses with acceleration magnitudes of between 5,000-25,000 g and primary pulse durations from 20-50 $\mu \mathrm{s}$, as documented by Kelly et al. [9-11]. The frequency range of the VAMP analysis is $0-19 \mathrm{kHz}$ and it is shown how manipulation of the VAMP parameters can effectively control the dominant signal frequency components. This is an extension to current shock standards such as the MIL-STD-810G [12] which require a frequency response from $0-10 \mathrm{kHz}$. The analysis of the higher frequency data is an important aspect of the work. It permits direct application of the VAMP acceleration data to test MEMS devices within a frequency bandwidth of $0-19 \mathrm{kHz}$.

The ultimate impact is analysed for a range of parameters in order to find the optimum configuration to obtain clean, repeatable shock pulses. The pulse shaping test rod material is varied between titanium and copper-beryllium. The diameter of the test rods is kept constant at $10 \mathrm{~mm}$ and the test rod length is varied between $60,90 \mathrm{and} 120 \mathrm{~mm}$. Impact interface conditions are varied by altering the test rod geometry and introducing mitigators at the impact interface, which plastically deform on impact. Isolation of the striker and incident test rods is achieved by aluminium carriers with embedded O-rings, which partially enclose the test rods and act as effective Coulomb dampers during impact to negate the effect of clattering. The primary application for the VAMP is envisaged as a small-form factor shock tester. To this end, an accelerometer is fixed to the end of the incident test rod, and this can be substituted for a micro-device in order to conduct high-acceleration shock testing.

The objectives of the paper are as follows:

- to design and characterise a small-form factor VAMP shock tester to generate high-acceleration shock pulses of controllable acceleration magnitude and primary pulse duration.

- to investigate the pulse shaping characteristics of the test rods when subjected to a HPB generated incident compression pulse. 


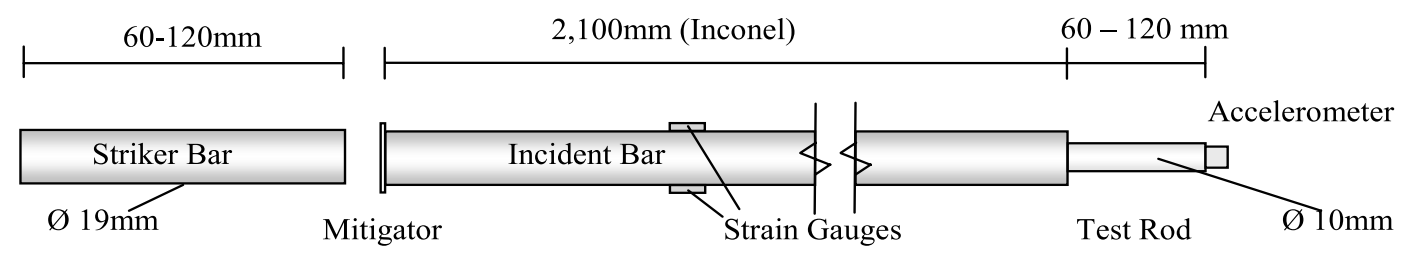

Fig. 2. Hopkinson pressure bar apparatus.

- to investigate the controllable parameters that affect the shock pulses induced on collision, namely; test rod material; test rod length; pulse shaping mechanisms; and impact velocity.

- to examine the mechanical isolation of striker and incident test rods in the VAMP through the use of Coulomb damper carriers to simulate the ideal case of a controlled HPB shock test.

Time-frequency signal analysis techniques are also applied to establish the spectral content of the resulting acceleration pulses and to identify appropriate application areas for the VAMP shock tester.

The first section of the paper outlines the equipment and procedures that were followed to carry out the experimentation. The experimental results are then presented with supporting signal analysis work and a discussion of their significance before stating the key conclusions.

\section{Experimentation}

In this section, the experimental apparatus and procedures are outlined. The HPB apparatus is presented first before moving on to the VAMP. The HPB is used in order verify the characteristics of the acceleration shock pulses, by employing the small-scale VAMP test rods as fly-away devices on the end of the HPB incident bar, as a direct reference for the VAMP results.

\subsection{Hopkinson pressure bar}

The HPB apparatus was set up as presented in Fig. 2. The apparatus consisted of $19 \mathrm{~mm}$ diameter, Inconel 718 , striker and incident bars. HPB striker bars 60-120 mm long were used and the HPB incident bar was 2,100 mm long, and instrumented with diametrically-opposed $3 \mathrm{~mm}$ Vishay $350 \Omega$ strain gauges at its centre. Strain gauge data was amplified by a Vishay 2110 signal conditioner, low pass filtered at $15 \mathrm{kHz}$ with a bridge excitation of $2.5 \mathrm{~V}$ and recorded by a Fluke PM3394A Oscilloscope at $2.5 \mathrm{MHz}$.

A National Instruments PCI 6251 data acquisition card was used in conjunction with a LabVIEW programme on a $3.2 \mathrm{GHz}$ PC to sample the acceleration data at $1.25 \mathrm{MHz}$. A National Instruments SC-2345 Signal Conditioner powered the accelerometer with an SCC-ACC-01 acceleration module. The SCC-ACC01 accelerometer input module accepts an active accelerometer input signal, passes it through a $0.8 \mathrm{~Hz}$ high-pass filter, amplifies it by a factor of 2 and then passes it through a $19 \mathrm{kHz} 3$-pole low-pass Bessel filter and an output buffer. A uni-axial IEPE powered 3200B Dytran accelerometer was attached to the end of the test rod as shown in Fig. 2. The accelerometer had a range of $\pm 80,000 \mathrm{~g}$, a sensitivity of $0.05 \mathrm{mV} / \mathrm{g}$ and a linear frequency response from $0-20 \mathrm{kHz}$. A single thickness of stationary card $0.2 \mathrm{~mm}$ thick was used as a mitigator to remove the high-frequency components from the strain signal. The mitigator effectively smoothes the input compression pulse, negating the effect of dispersion in the incident bar as the high frequencies are suppressed. The test rods were bonded onto the end of the incident bar with cyanoacrylate to position the test rods for testing.

The HPB apparatus was set up as shown in Fig. 2. Each test rod was attached to the end of the incident bar in turn. The striker bar was launched at velocities between 3.2-6.0 m/s at the opposite end of the incident bar. On impact with the incident bar, a compression pulse propagated along the incident bar and transmitted into the test rod. On refection from the end of the test rod, the tensile force generated at the incident bar/test rod interface caused the test rod to separate from the end of the incident bar allowing for a single pulse loading of the test rod for each experimental test. 


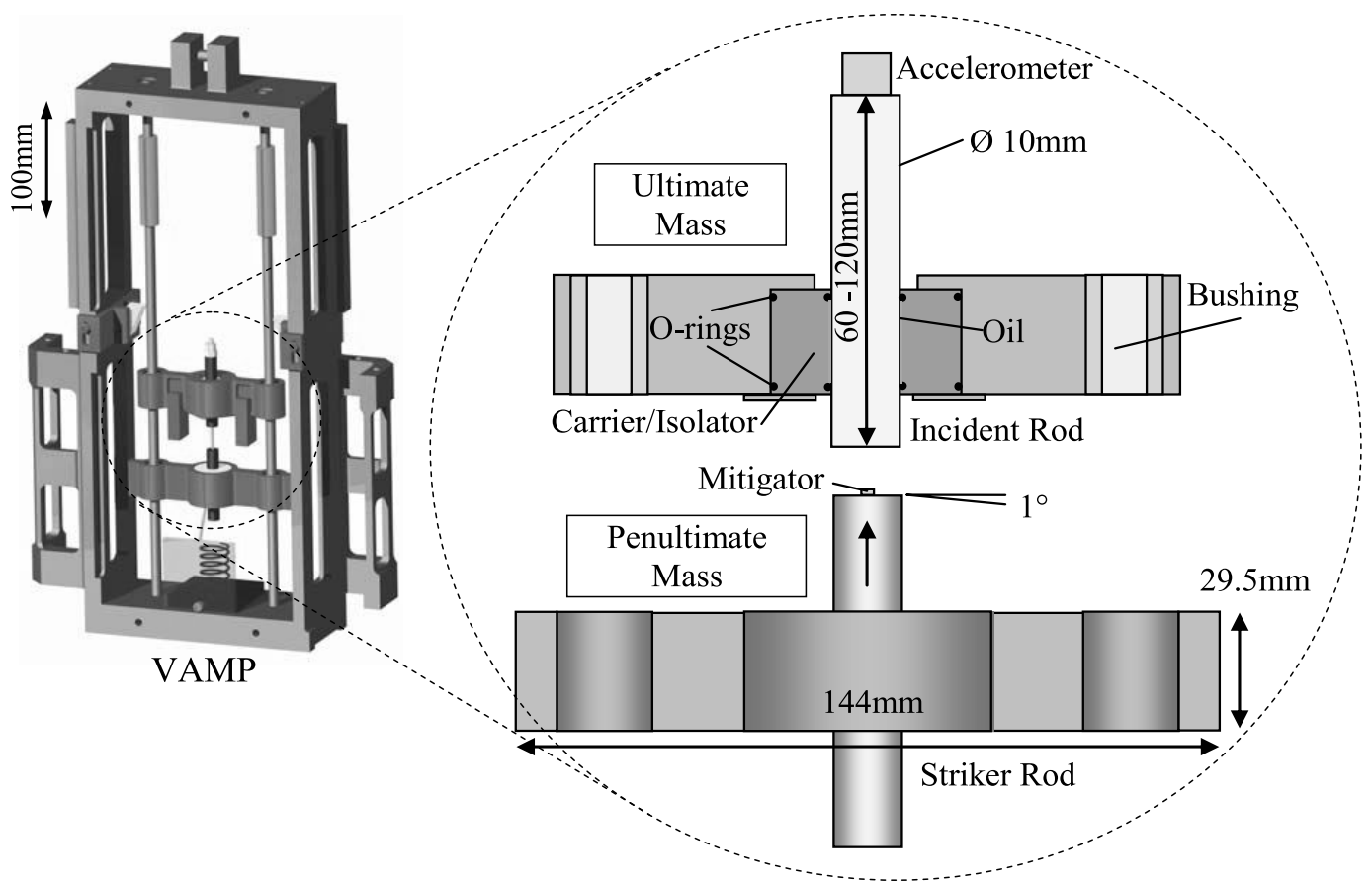

Fig. 3. VAMP model highlighting the penultimate and ultimate masses with interchangeable test rod cores.

\subsection{Velocity amplifier shock tester}

The VAMP was integrated within the crosshead of the Instron $9250 \mathrm{HV}$ drop tester as displayed in Fig. 3. A cross section of the ultimate mass and the penultimate mass is also shown, illustrating the critical aspects of the VAMP design.

The critical features of the VAMP are as follows:

- Carrier/Isolator: The carrier was employed to avoid multiple impacts, isolate the test rods from any complex geometry and minimise the effect of stress wave propagation on impact. It acted as an effective Coulomb damper in each mass by opposing the vertical motion of the striker and incident test rods with a negligible spring component in order to nullify the possibility of multiple impacts.

- Mitigator: Annealed copper discs, $0.5 \mathrm{~mm}$ thick and $3 \mathrm{~mm}$ diameter were used as mitigators to remove the high frequency components in the acceleration signal. Plastic deformation of the mitigator on impact increases the pulse duration at the expense of acceleration magnitude.

- Test Rod: The striker test rod was held in the penultimate mass and the incident test rod in the ultimate mass. A range of $10 \mathrm{~mm}$ diameter test rods was used. Test rod material was varied between titanium and copper-beryllium and the test rod length between $60 \mathrm{~mm}, 90 \mathrm{~mm}$ and $120 \mathrm{~mm}$.

The data acquisition and signal conditioning applied to the VAMP acceleration data was identical to that documented for the HPB acceleration data. Selected drop tests were recorded using an IDT XStream XS-4 CMOS high-speed camera, which recorded the drop event at between 5,000-100,000 frames per second, dependent on the area of interest.

The VAMP was first attached to the drop tester as the acting crosshead. The crosshead was raised to the required height in the drop tester using the drop test interface. The crosshead was released and the accelerometer signal was recorded by the data acquisition system. This process was repeated to generate a statistical sample of 10 drop tests for each test setup. The drop heights tested from 50-200 mm resulted in an impact velocity range of 3.5-5.8 m/s between the ultimate and penultimate masses, which was calculated from the high-speed imaging. 


\section{Results and discussion}

This section contains the results from the HPB and VAMP experimentation, a discussion of the significant outcomes, and a comparison between the HPB and VAMP test methods. A modal analysis of the test rods is presented first in order to establish if test rod resonant effects affect the experimental instrumentation. The acceleration pulse shape is examined for a range of test rod parameters on the HPB and VAMP, and the effect of each parameter on the pulse is evaluated in order to obtain the optimum setup for the ultimate and penultimate masses in the VAMP. The acceleration results are investigated with signal analysis tools which aid in deciphering the spectral content of the acceleration data and strengthen the applicability of the research to testing micro-scale devices.

\subsection{Modal analysis}

A modal analysis of the test rods was carried out using ANSYS 11.0 finite element software package in order to anticipate the modal frequencies of interest for the VAMP shock pulse shaping. Solid 9520 -node brick elements were applied and a Block Lanczos modal analysis was carried out for the required modes between $1-150 \mathrm{kHz}$. The axial modes were of primary importance due to the impact orientation of the test rods. The model boundary conditions incorporated the constraints of the aluminium carrier and the mounted accelerometer as displayed in Fig. 3. The first axial mode for the $120 \mathrm{~mm}$ long, $10 \mathrm{~mm}$ diameter titanium test rod was $21.5 \mathrm{kHz}$. The most important point to note was that all axial modes - with the exception of the first axial mode for the $120 \mathrm{~mm}$ long copper-beryllium test rod at $16.5 \mathrm{kHz}$ - were greater than $20 \mathrm{kHz}$. This implies that any resonant effect due to axial modal frequencies will be filtered by the experimental signal conditioner.

\subsection{Hopkinson pressure bar}

The HPB represents the state-of-the-art in controlled high-acceleration shock testing. The HPB testing was carried out to verify the characteristics of the acceleration shock pulses, by employing the small-scale VAMP test rods as fly-away devices on the end of the HPB incident bar, as a direct reference for the VAMP results. An industry-standard HPB was used to test the pulse shaping effects on the full array of test rods using Inconel bars.

The experimental tests applied Inconel striker bars of 60-120 mm in length in order for the pulse duration to compare directly with the VAMP test results. The Inconel bars also used a $0.2 \mathrm{~mm}$ thick stationary card as mitigation at the impact interface between the striker and incident bars. The low thickness of the mitigator had the effect of protecting the compression-type piezoelectric accelerometer from the very high frequency components of the input signal without appreciably altering the shape of the acceleration pulse. Strain gauge and accelerometer data was compared and each experimental test exhibited less than 5\% and 10\% difference in terms of acceleration magnitude and primary pulse duration respectively. This was deemed an acceptable degree of comparison between the strain gauge and accelerometer data as Rogillio et al. [13] and Gama et al. [14] state that 4-6\% is a typical level of discrepancy between strain gauge and accelerometer readings for bars of matching impedance.

It was established that employing the short test rods caused reflective interference in the acceleration signal following the initial pulse, and attenuation of the residual signal oscillations. This led to a close approximation of a uni-modal acceleration pulse, with minimal oscillatory behaviour subsequent to the primary acceleration pulse. Fig. 4 presents the accelerometer data with impact velocities of $6 \mathrm{~m} / \mathrm{s}$ for the $120 \mathrm{~mm}$ long striker bar and $5 \mathrm{~m} / \mathrm{s}$ for the 90 and $60 \mathrm{~mm}$ long striker bars respectively. The legend indicates the test rod material followed by the striker bar length followed by the incident test rod length. Effectively;

- Ti - 120 - 90 denotes a titanium test rod, $120 \mathrm{~mm}$ long striker bar and $90 \mathrm{~mm}$ long incident test rod affixed on the end of the HPB.

This representation scheme is used throughout the paper.

The acceleration magnitude levels in Fig. 4 compare well for the $\mathrm{Ti}-90-90$ and $\mathrm{Ti}-60-60$ test configurations due to the similar impact velocity in each test. Each acceleration signal displays a similar rate of roll-off with a roll-off of $-15,000 \mathrm{~g} /$ period for the $\mathrm{Ti}-120-90$ configuration (a slope of $-251 \mathrm{~g} / \mu$ s for the linear approximation). The variation in the primary pulse duration is dependent on the geometry of the striker bar, with longer pulse 
Table 1

Acceleration primary pulse range for the Inconel HPB

\begin{tabular}{lccc}
\hline $\begin{array}{l}\text { Test rod material }- \\
\text { striker - incident }(\mathrm{mm})\end{array}$ & Impact velocity $(\mathrm{m} / \mathrm{s})$ & $\begin{array}{c}\text { Primary pulse duration } \\
(\mu \mathrm{s})\end{array}$ & $\begin{array}{c}\text { Maximum acceleration } \\
(\mathrm{g})\end{array}$ \\
\hline $\mathrm{Ti}-60-120$ & 5 & 45.0 & 18,157 \\
$\mathrm{Ti}-90-120$ & 5 & 48.8 & 18,378 \\
$\mathrm{Ti}-120-120$ & 6 & 52.0 & 24,661 \\
$\mathrm{Ti}-60-90$ & 5 & 40.8 & 20,103 \\
$\mathrm{Ti}-90-90$ & 5 & 44.8 & 21,073 \\
$\mathrm{Ti}-120-90$ & 6 & 44.8 & 27,255 \\
\hline
\end{tabular}

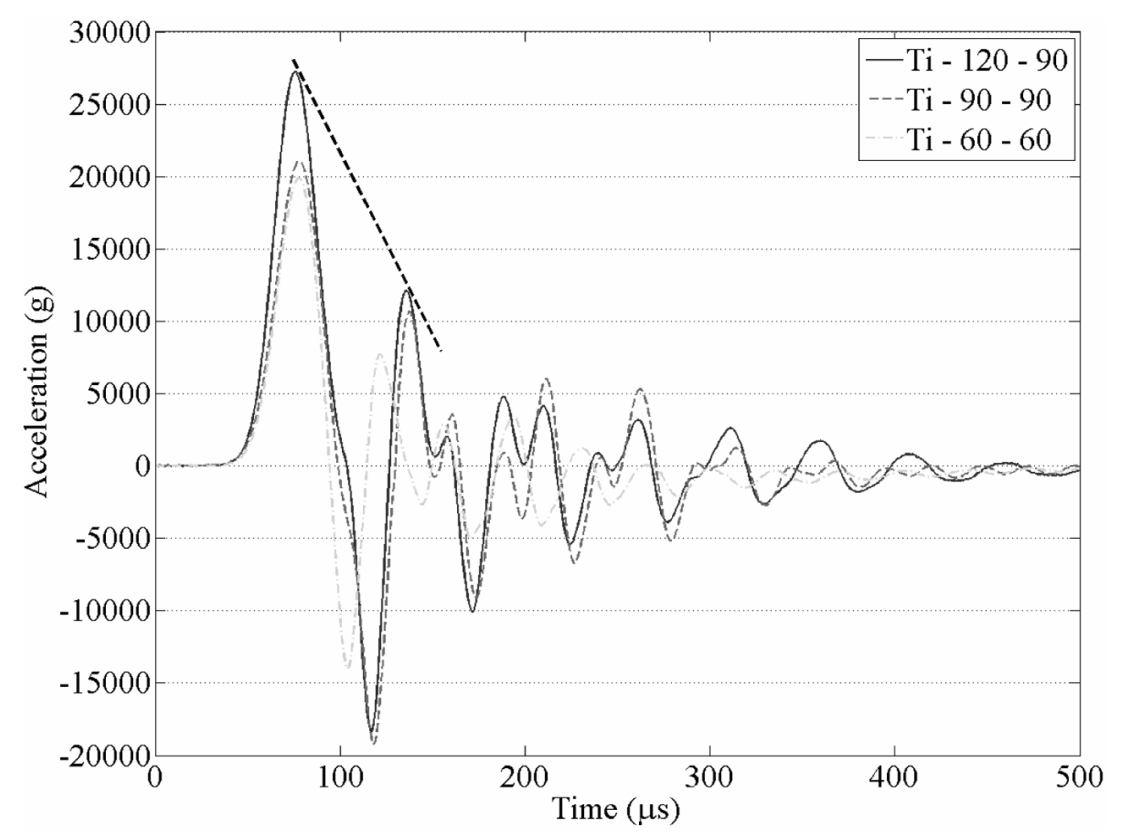

Fig. 4. Comparison of acceleration traces for the 120, 90 and $60 \mathrm{~mm}$ long striker bars and the 60 and $90 \mathrm{~mm}$ long titanium test rods.

durations recorded for longer striker bars. The acceleration signals are therefore a close approximation to the ideal case of a uni-modal shock pulse leading to a single pulse loading for an attached micro-device. A sample of the range of acceleration data for the Inconel HPB testing is tabulated in Table 1.

A statistical sample of five tests was performed for the $\mathrm{Ti}-60-120$ data presented in Table 1 for an impact velocity of $5 \mathrm{~m} / \mathrm{s}$. The average maximum acceleration over the five tests was $18,157 \mathrm{~g}$ with a standard deviation of $7 \%$ of the average. The average primary pulse duration was $45.0 \mu \mathrm{s}$ for the five tests with a standard deviation of $4.9 \%$, with the average duration of the half-period residual oscillations at $30.2 \mu$ s. The primary pulse duration was consistently computed using the guidelines outlined by Wilson [15].

The acceleration magnitude increased with impact velocity to a maximum of $27,255 \mathrm{~g}$ for a $6 \mathrm{~m} / \mathrm{s}$ impact velocity employing the $120 \mathrm{~mm}$ striker bar and the $90 \mathrm{~mm}$ titanium test rod. Primary pulse duration increased with striker bar length. As the HPB was the secondary form of experimentation in this research, the data range established was sufficient as a point of reference for the VAMP results.

\subsection{Velocity amplifier shock tester}

This section examines the acceleration results obtained from the VAMP testing where the effect of a range of parameters on the acceleration pulse shape is evaluated, in order to obtain the optimum setup for the ultimate and penultimate masses. The effect of the following parameters on the acceleration shock pulse was analysed:

- Test rod material 


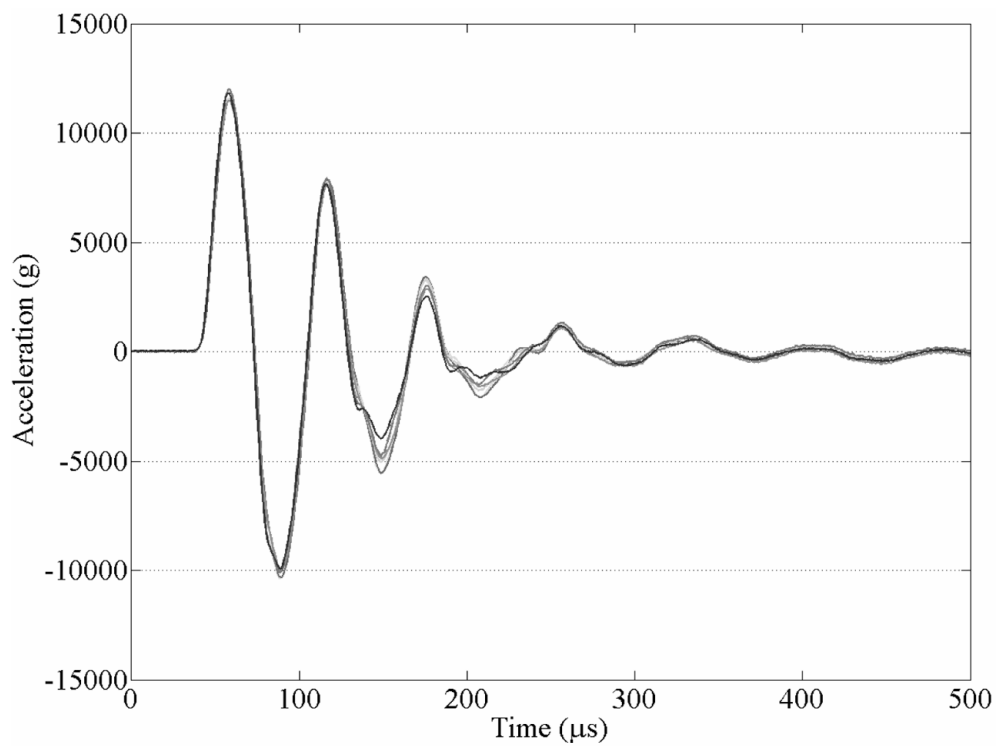

Fig. 5. VAMP acceleration plots displaying the repeatability of the pulse shape for six tests applying a consistent impact velocity of $3.5 \mathrm{~m} / \mathrm{s}$ for each test.

- Test rod geometry

- Drop height and resulting impact velocity

- Impact interface and use of mitigators between striker and incident rods

The VAMP data is compared directly with the HPB data to evaluate the attributes of the VAMP acceleration data. The accelerometer signal conditioner module low-pass filtered the acceleration data at $19 \mathrm{kHz}$ to ensure operation within the linear response region of the accelerometer. For practical VAMP applications, suitable mechanical filtering [16, 17] at $19 \mathrm{kHz}$ is required for the micro-device under test to negate the effect of high frequency components.

\subsubsection{Repeatability and test rod geometry}

The acceleration plots in Fig. 5 show the complex acceleration signal for six identical drop tests using the VAMP and demonstrate the shape of the acceleration pulse to be consistent with a decaying sinusoid, with a roll-off of approximately $4,300 \mathrm{~g} /$ period. Each drop height of $50 \mathrm{~mm}$ resulted in an impact velocity of $3.5 \mathrm{~m} / \mathrm{s}$ for a Ti $60-120$ configuration. Each plot possesses similar characteristics in terms of pulse magnitude and pulse length, demonstrating the repeatability of the acceleration pulses. Average peak acceleration and primary pulse duration for the six traces is $11,671 \mathrm{~g}$ and $28.7 \mu \mathrm{s}$, with standard deviations of $1.70 \%$ and $1.14 \%$ of the mean values respectively, verifying the repeatability.

The titanium test rods were established as the optimum pulse shaping test rods for the VAMP due to their low mass, and they formed the primary focus of all VAMP test results. Having established the repeatability of acceleration pulse shape, the variation in test rod length for the titanium test rods was considered. Figure 6 plots the VAMP acceleration pulses for an impact velocity of $3.5 \mathrm{~m} / \mathrm{s}$ and a $120 \mathrm{~mm}$ long incident rod while varying the striker length.

The acceleration pulse shapes presented in Fig. 6 follow a trend of increased primary pulse duration for greater striker rod length. The primary pulse duration exhibited for each test is higher than that predicted for simple 1-D wave propagation with $28.0 \mu$ s for the $60 \mathrm{~mm}$ striker versus $11.8 \mu$ s for the theoretical case. This increase in primary pulse duration was due to the following factors:

- increased titanium striker test rod length,

- complexities at the impact interface from local elastic deformation and the inherent difficulties in ensuring a flat-flat impact,

- the low-pass filtering applied by the acceleration signal conditioner module,

- stress wave transmission through the aluminium carriers. 


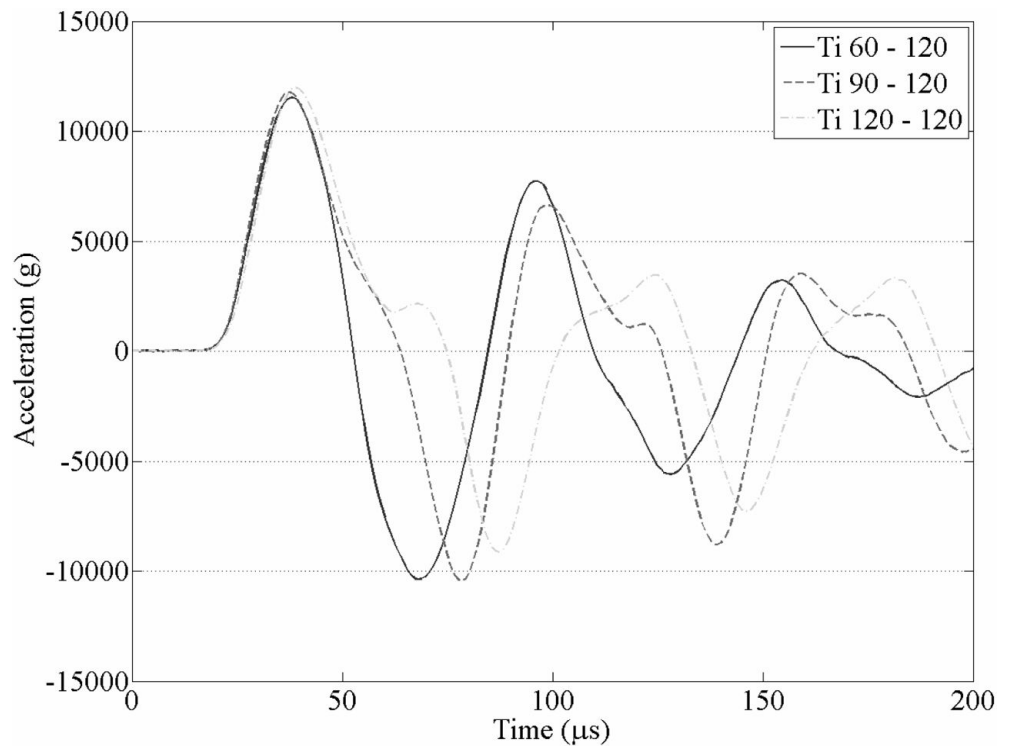

Fig. 6. VAMP acceleration traces for a series of titanium striker rod lengths and an impact velocity of $3.5 \mathrm{~m} / \mathrm{s}$.

\subsubsection{Impact interface and mitigator use}

The primary VAMP configuration is a flat-flat, metal-on-metal finite collinear rod impact resulting in a highfrequency high-acceleration shock pulse. Geometry variations of test rod length have been presented in Fig. 6 to vary the pulse shape. Another method of pulse shaping is to alter the impact interface with the effect of extending the primary pulse duration and decreasing the acceleration magnitude. The application of annealed copper mitigators between the test rods will now be investigated, which plastically deform on impact in order to extend the impact duration.

The use of annealed copper discs as mitigators has been extensively documented in HPB pulse shaping studies by Frew et al. [18-20]. In VAMP testing, annealed copper discs - $3 \mathrm{~mm}$ diameter and $0.5 \mathrm{~mm}$ thickness - were applied as mitigators between the striker and incident test rods. On impact, the plastic deformation of the copper prolonged the impact with an associated increase in primary pulse duration and decrease in acceleration magnitude. Figure 7 represents the effect of using a mitigator at the impact interface between the striker and incident rods. Acceleration plots from a flat-flat impact for a $\mathrm{Ti}-60$ - 120 configuration are compared directly with plots when using mitigation for impact velocities of 3.5 and $5.1 \mathrm{~m} / \mathrm{s}$. The resulting acceleration plots for the use of mitigators have much slower ramp rates due to the plastic deformation.

Figure 7 illustrates how the $46 \%$ increase in impact velocity affects the acceleration pulse shape with and without the copper mitigator. The application of the mitigator for a $3.5 \mathrm{~m} / \mathrm{s}$ impact velocity resulted in a $56.7 \%$ increase in primary pulse duration from 29.6 to $46.4 \mu \mathrm{s}$ and a $54.6 \%$ decrease in acceleration magnitude from 11,520 to 5,235 g. This compares well with the VAMP data for an increased impact velocity of $5.1 \mathrm{~m} / \mathrm{s}$. The elevated impact velocity generated a $55.6 \%$ increase in primary pulse duration from 28.8 to $44.8 \mu \mathrm{s}$ and a $53.5 \%$ decrease in acceleration magnitude from 19,535 to 9,092 g. Therefore, the effect of mitigation scales well in terms of acceleration magnitude and exhibits a negligible difference in the primary pulse duration for increasing impact velocity.

\subsubsection{Acceleration pulse range}

Having outlined the effects of varying each parameter on the VAMP, a quantitative analysis of the acceleration magnitude and primary pulse duration for the full range of test rods is now considered. This section compares the attributes of the VAMP acceleration pulse for the full range of parameters. Figure 8 plots the average maximum acceleration against impact velocity for a statistical sample of ten tests for a selection of test rods and pulse shaping mechanisms. The Ti-60-120 Cu Mitigator configuration denotes use of the plastically deformable mitigators at the impact interface. 


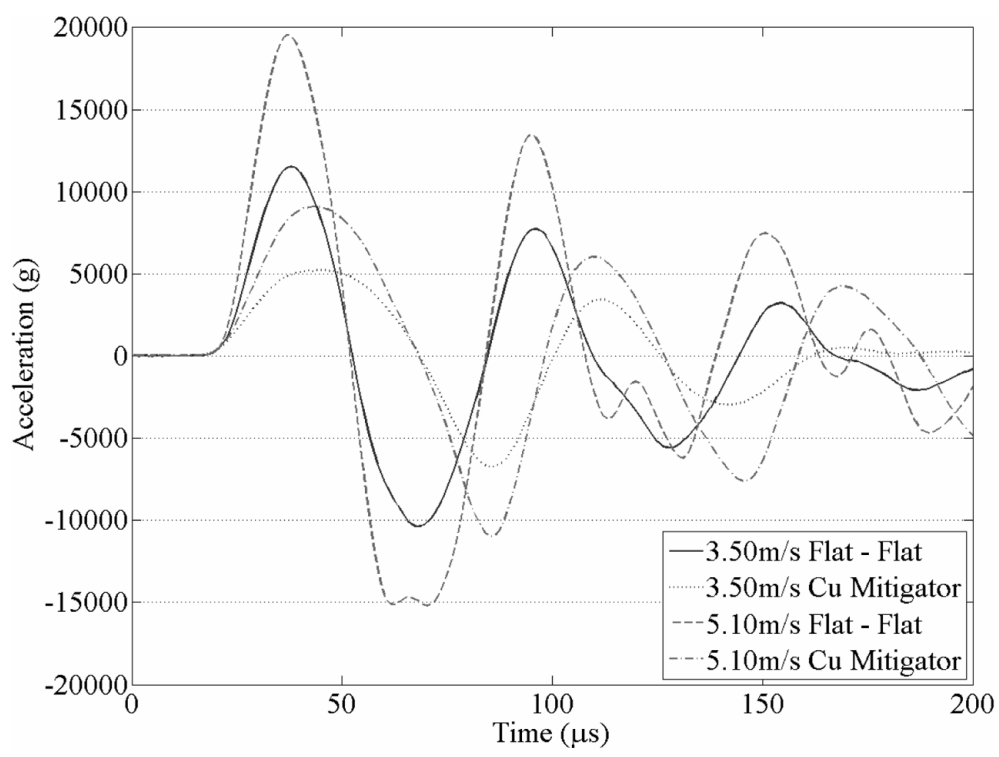

Fig. 7. VAMP acceleration traces displaying the effects of applying annealed copper mitigators with the $\mathrm{Ti}-60-120$ configuration.

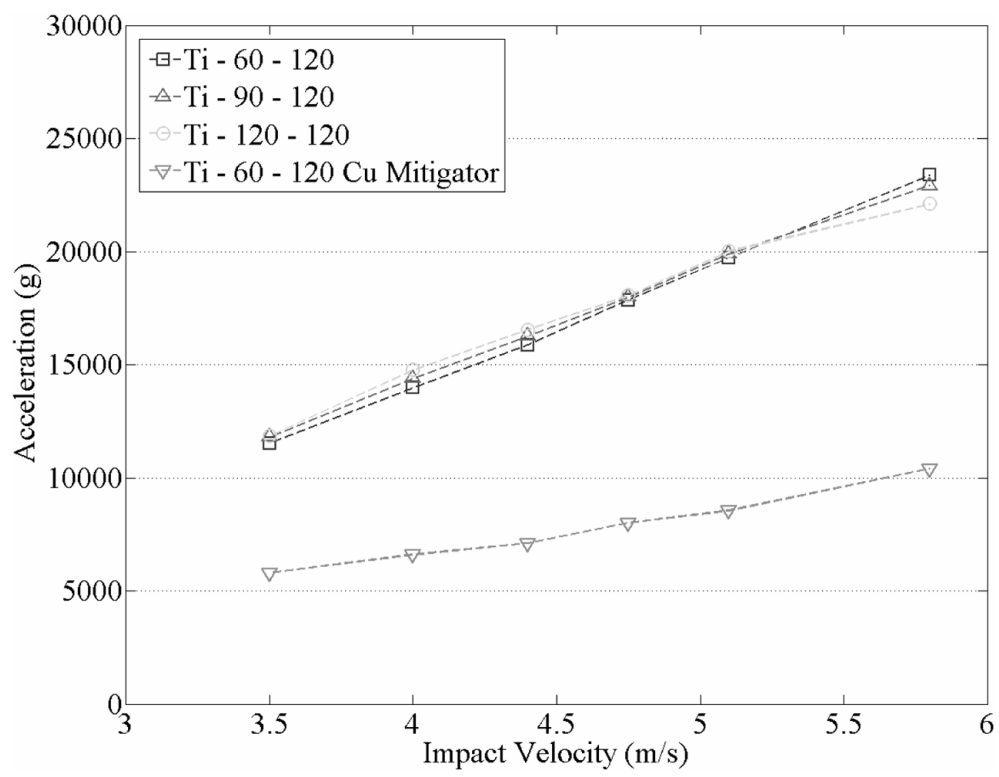

Fig. 8. Maximum acceleration plotted against impact velocity for a range of test rods and pulse shaping mechanisms. The broken lines between data points represent an indicative curve-fit.

The titanium test rods in Fig. 8 demonstrate consistent acceleration levels for varying striker rod length. Moreover, the titanium rods illustrate a linear acceleration increase with impact velocity with an approximate slope of $5,181 \mathrm{~g} /(\mathrm{m} / \mathrm{s})$ for the $\mathrm{Ti}-60-120$ configuration. It can thus be inferred that much higher acceleration levels are obtainable for higher drops, resulting in greater impact velocities. This body of work has not researched accelerations over $30,000 \mathrm{~g}$ as very high drop testing would decrease the lifespan of the test facility. The plot representing the use of annealed copper mitigators displays a much lower ramp rate with a linear acceleration increase and a slope of $1,980 \mathrm{~g} /(\mathrm{m} / \mathrm{s})$ for the data presented.

Having outlined the range of acceleration pulse shapes achieved through VAMP shock testing, it is instructive to compare the VAMP data with the HPB data in terms of acceleration magnitude and primary pulse duration. Figure 9 


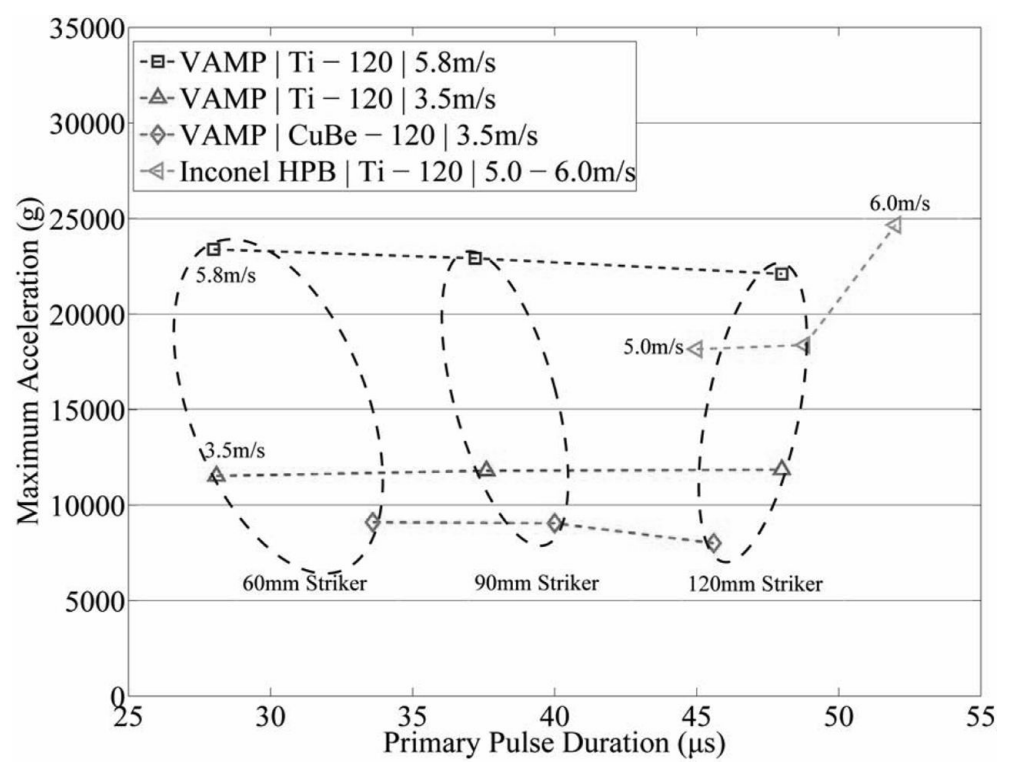

Fig. 9. Acceleration pulse range for each experimental method in terms of acceleration magnitude and primary pulse duration. The broken lines between data points represent an indicative curve-fit.

plots the acceleration pulse ranges for the following experimental methods:

- VAMP

- HPB - VAMP approximation - Inconel bars

All data presented was obtained using the $120 \mathrm{~mm}$ long incident test rods. The striker test rod length was increased from $60-120 \mathrm{~mm}$ to increase the primary pulse duration accordingly for the VAMP and Inconel HPB tests as annotated for the VAMP data in Fig. 9.

Loci for the titanium test rods are plotted in Fig. 9 for minimum and maximum impact velocities of 3.5 and $5.8 \mathrm{~m} / \mathrm{s}$ for clarity. Inconel HPB data is displayed for the $120 \mathrm{~mm}$ titanium test rod and compares well with the VAMP data in terms of acceleration magnitude. The VAMP titanium test rod loci are well ordered and of a consistent slope for the 3.5 and $5.8 \mathrm{~m} / \mathrm{s}$ impact data with increased pulse duration for greater striker rod length. The copper-beryllium data displays greater pulse duration for the $60 \mathrm{~mm}$ striker rod with respect to the titanium loci.

- The pulse duration increase, relative to striker rod length is consistent for each material.

- The largest primary pulse duration range of $28.0-48.0 \mu \mathrm{s}$ is exhibited by the titanium test rods.

- The variation in pulse duration range between materials is due to the variation in stress wave speed and the dynamic behaviour of each material under mechanical shock.

The greater mass for the copper-beryllium test rods results in higher contact forces on impact than for the titanium test rods. This leads to increased local elastic deformation with impact velocity, and associated shorter primary pulse duration for the copper-beryllium test rods as the impact interface more closely approximates planar contact. The $\mathrm{Ti}-60$ - 120 was the optimum configuration resulting in acceleration pulses closely approximating a decaying sinusoid as plotted in Fig. 5.

The maximum acceleration levels for the Inconel HPB data represent impact velocities of 5 and $6 \mathrm{~m} / \mathrm{s}$, which compare closely with the VAMP data for an impact velocity of $5.8 \mathrm{~m} / \mathrm{s}$. The Inconel HPB loci displays greater primary pulse duration than the VAMP due to dispersion effects in the 2,100 mm long HPB incident bar as a result of the minimal mitigation applied to approximate the VAMP test case. The dispersion leads to an increased rise-time and primary pulse duration as evidenced in Fig. 4 for the Inconel HPB acceleration data. 


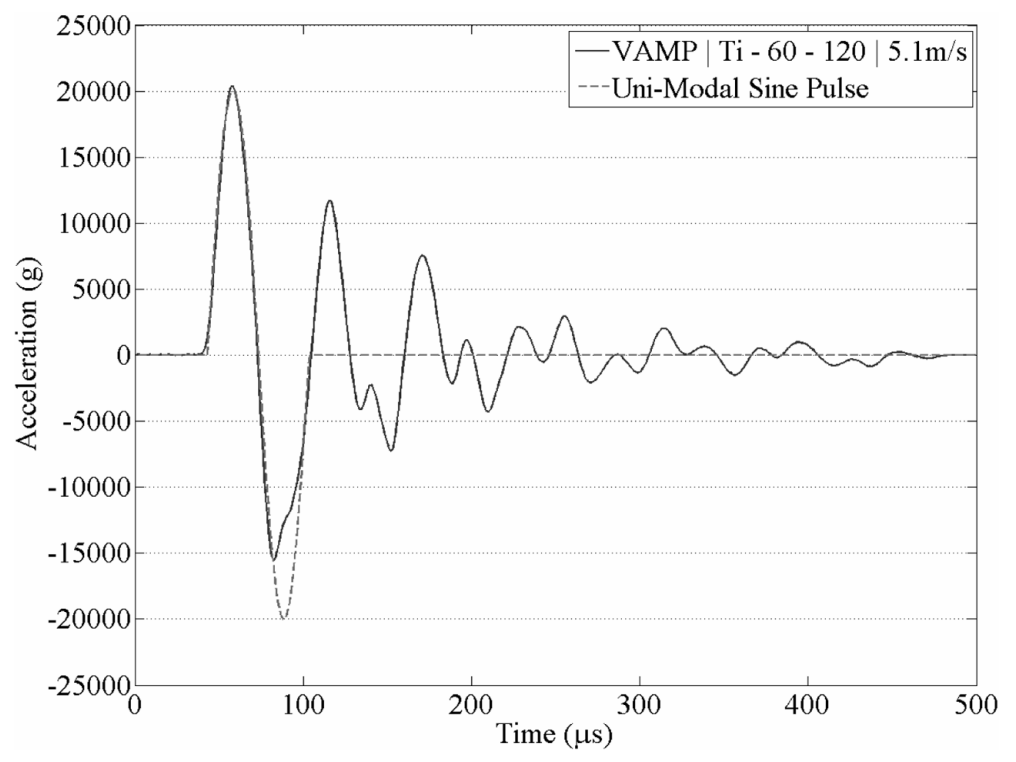

Fig. 10. Input acceleration data for each signal analysis process.

\subsection{Signal analysis}

Signal analysis tools are applied to the experimental acceleration signals to investigate the spectral content of the signals in order to determine the utility of the shock data. The signal analysis tools applied to the experimental data are listed as follows:

- Shock Response Spectrum (SRS)

- Harmonic Wavelet Transform (HWT)

- Energy Input Spectrum (EIS)

\subsubsection{Shock response spectrum}

Figure 10 plots the acceleration traces that were used as input for each signal analysis method. The VAMP pulse was recorded from the optimum $\mathrm{Ti}-60-120$ configuration. The uni-modal sine pulse was modelled on the VAMP acceleration trace with similar primary pulse duration and acceleration magnitude as outlined by Goyal [21]. The SRS plotted in Fig. 11 was computed using a ramp invariant digital filter simulation of the SDOF system in accordance with the ISO standard for the computation of the SRS [22], with the critical damping, $\xi$, set at 5\% for each test.

From inspection of Fig. 11, the similarity between the SRS for the VAMP and uni-modal sine pulse is clear; with the sine pulse SRS encompassing the majority of the VAMP SRS with the exception of the low frequency response to the VAMP acceleration excitation. The peak acceleration of the VAMP data in Fig. 11 is 56,655 $\mathrm{g}$ at a frequency of $17.6 \mathrm{kHz}$. This is important in the context of practical applications where MEMS devices can be tested to excite specific resonances at predetermined acceleration levels using the VAMP.

\subsubsection{Harmonic wavelet transform}

The limitations of the SRS are well documented by Smallwood [23], with the primary limitation being the loss of all temporal information in the SRS. The HWT is an alternative tool for time-frequency analysis as it retains the temporal information in a 3-D plot. A modified version of the original HWT, proposed by Newland [24], was applied here.

Figure 12 plots the HWT data for a VAMP Ti - 60 - 120 acceleration trace as illustrated in Fig. 10. The 3-D contour plot represents time, frequency and energy spectral density on the $\mathrm{x}-, \mathrm{y}-\mathrm{and} \mathrm{z}$-axes respectively. The retention of the temporal information is important as it affords a more detailed analysis of the acceleration signal 


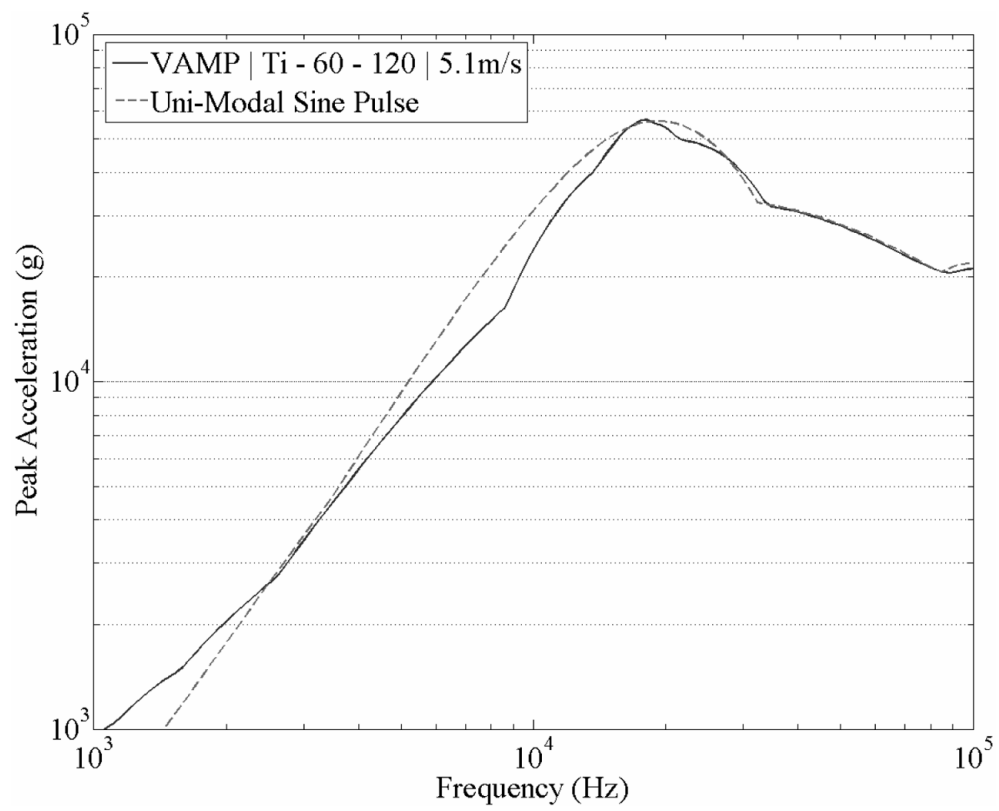

Fig. 11. SRS for VAMP and uni-modal sine pulse.

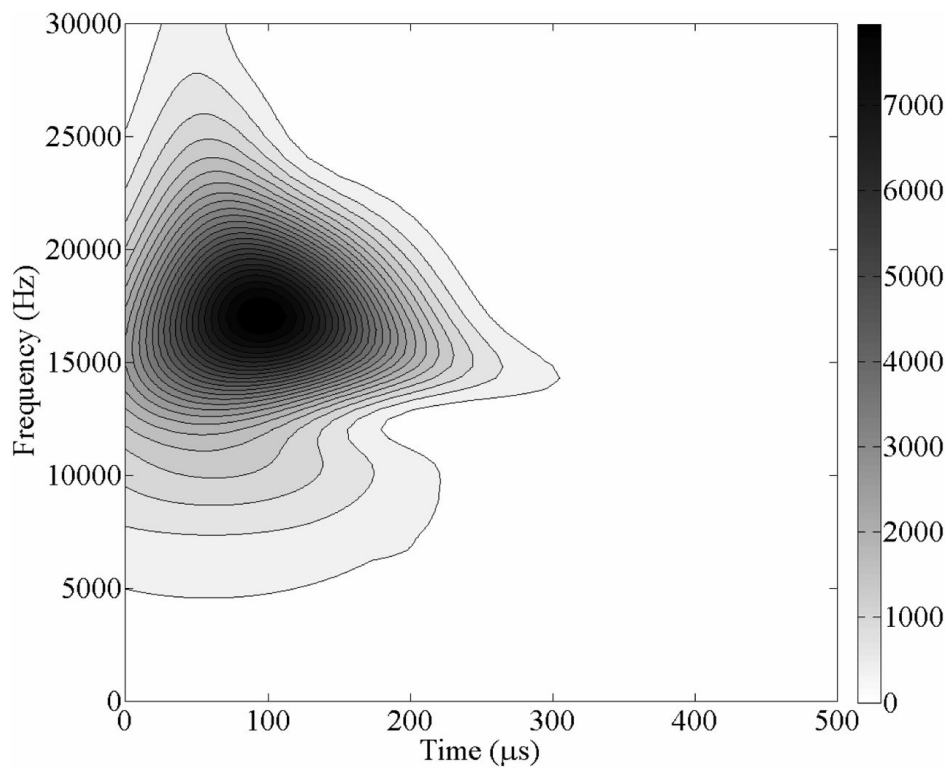

Fig. 12. HWT contour plot of VAMP Ti $-60-120$ acceleration trace.

frequency content. The energy spectral density was normalised in order that the volume under the HWT surface corresponds to the energy of the original acceleration signal. The maximum energy spectral density of $7,750 \mathrm{~g}^{2} /(\mathrm{Hz}$ s) is concentrated between $80-110 \mu$ s and $15.5-18.0 \mathrm{kHz}$ for the VAMP HWT in Fig. 12.

To illustrate the effect of altering the initial conditions of test rod material and length, a HWT was computed for a VAMP CuBe $-120-120$ acceleration trace, for an impact velocity of $5.1 \mathrm{~m} / \mathrm{s}$. The resulting HWT displays a maximum energy spectral density of $5,250\left(\mathrm{~g}^{2} /(\mathrm{Hz} \mathrm{s})\right)$ over a frequency bandwidth of $11.0-12.0 \mathrm{kHz}$. The critical signal parameters in the time and frequency domains for the representative VAMP acceleration traces and the uni-modal sine pulse are tabulated in Table 2. 
Table 2

Signal parameters for the representative acceleration signal traces

\begin{tabular}{lccc}
\hline Description & Uni-modal sine & $\mathrm{Ti}-60-120$ & $\mathrm{CuBe}-120-120$ \\
\hline Max Accel $(\mathrm{g})$ & 20,000 & 20,407 & 12,682 \\
Rise-time $(\mu \mathrm{s})$ & 10.4 & 10.4 & 15.2 \\
Primary Pulse Duration $(\mu \mathrm{s})$ & 28.0 & 28.0 & 55.2 \\
Max Energy $\left(\mathrm{g}^{2} /(\mathrm{Hz} \mathrm{s})\right)$ & 4,700 & 7,750 & 5,250 \\
Frequency Bandwidth $(\mathrm{kHz})$ & $15.0-18.0$ & $15.5-18.0$ & $11.0-12.0$ \\
Time $(\mu \mathrm{s})$ & $60-90$ & $80-110$ & $130-210$ \\
\hline
\end{tabular}

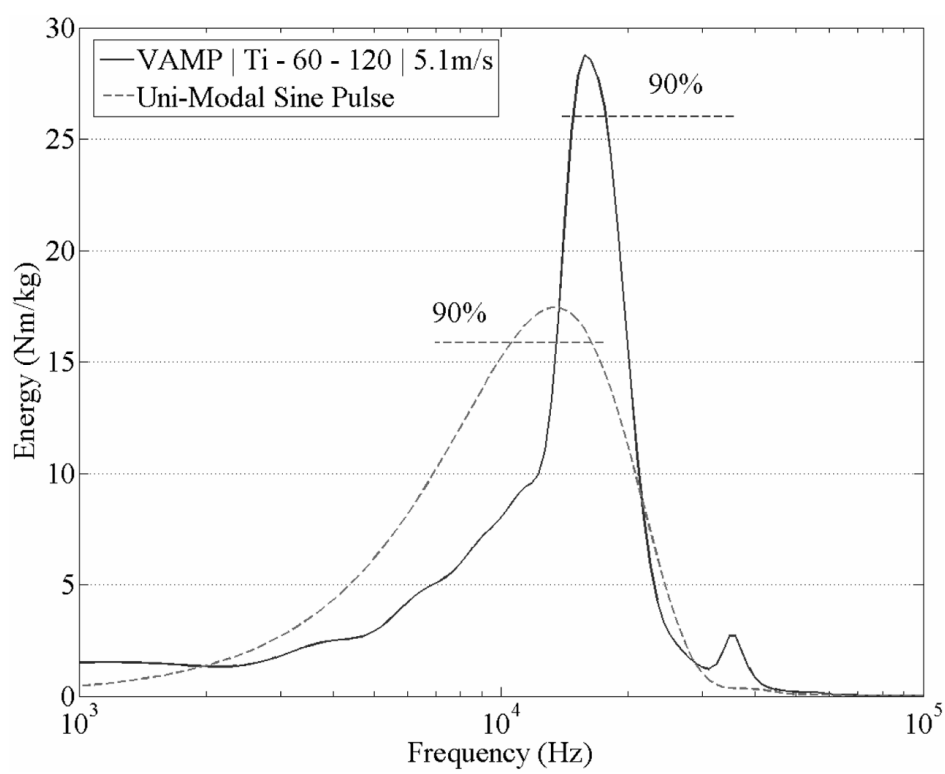

Fig. 13. Maximum energy input to an array of SDOF systems at their natural frequency for the VAMP and uni-modal sine acceleration pulse.

Table 2 illustrates how application of the HWT proves an effective method of investigating the energy content in the VAMP signals. It is concluded that the maximum energy spectral density for the VAMP Ti $-60-120$ signal is concentrated at $80-110 \mu \mathrm{s}$ in the time domain and between $15.5-18.0 \mathrm{kHz}$ in the frequency domain. Altering the VAMP initial conditions of test rod material and length demonstrates how the dominant signal frequency components can be controlled. This is critical in the context of practical VAMP applications, where control of the signal in the time and frequency domains is vital in order to effectively model an acceleration pulse to shock test a specific MEMS device.

\subsubsection{Energy input spectrum}

The EIS is computed as an improved representation of the damage potential of a shock in comparison to the SRS and is an accurate representation of the energy defined as the integral of force over a distance. The EIS is effectively a smoothed Fourier energy spectra and approximates the energy input to a SDOF by the acceleration signal, where the total energy is given in units of $\mathrm{Nm} / \mathrm{kg}$. Manipulation of the governing equations given by Smallwood and Edwards [25] leads to a derivation of the relative energies as follows:

Energy Input $(\mathrm{EI})=$ Energy Dissipated $(\mathrm{ED})+$ Kinetic Energy $(\mathrm{KE})+$ Energy Absorbed $(\mathrm{EA})$

The energy absorbed is the most important component as it relates to strain energy in the SDOF that can potentially lead to failure. The energy dissipated accounts for thermal and acoustical losses generated by the stress wave propagation through the linear SDOF system, and the kinetic energy is due to the rigid body translation. This is important in terms of practical applications for the VAMP, where the VAMP can be applied as a shock tester in current MEMS research such as micro-cantilevers under shock stimuli by Sheehy et al. [26]. For such an application, the VAMP pulse can be modelled in terms of magnitude and pulse duration to excite the MEMS device under test. 
Table 3

Energy input for the VAMP and uni-modal sine pulse acceleration signals

\begin{tabular}{lcc}
\hline Description & Ti-60-120 & Uni-modal sine \\
\hline Maximum Energy (Nm/kg) & 28.8 & 17.4 \\
Natural Frequency of SDOF System at Maximum Energy $(\mathrm{kHz})$ & 15.8 & 13.7 \\
Energy at 90\% of Maximum (Nm/kg) & 25.9 & 15.7 \\
Frequency Bandwidth at 90\% of Maximum Energy $(\mathrm{kHz})$ & $15.0-18.0$ & $10.5-16.5$ \\
\hline
\end{tabular}

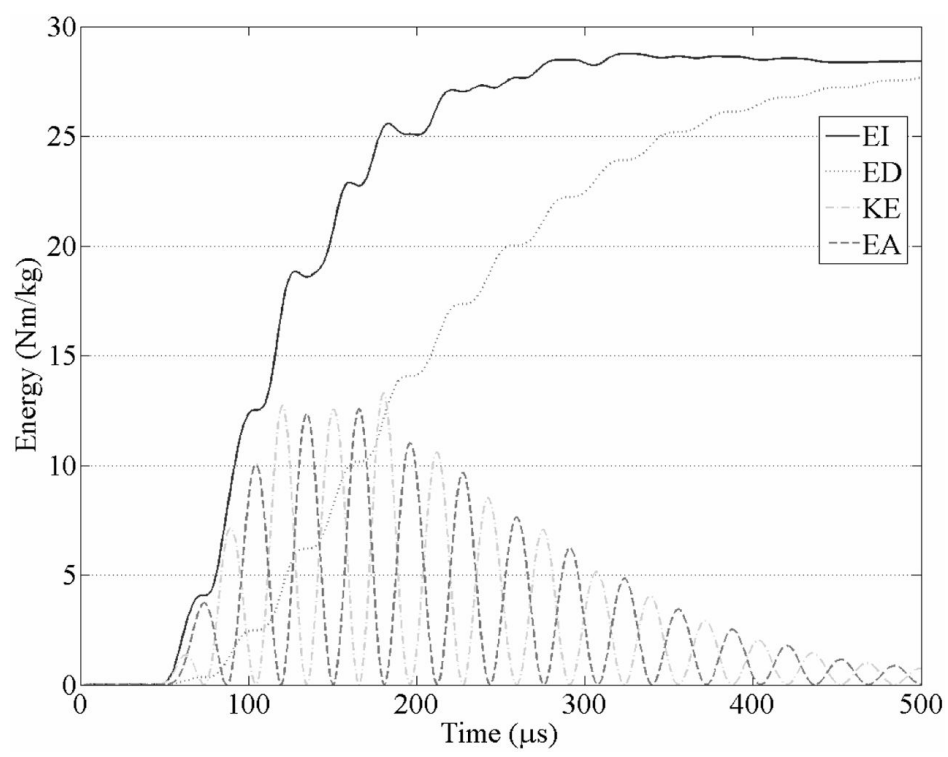

Fig. 14. EIS components for the VAMP acceleration pulse at $15.8 \mathrm{kHz}$.

Analysis of the EIS can then be used to investigate the damage potential of the VAMP shock pulses for a given MEMS device.

Figure 13 plots the maximum energy input against natural frequency for an array of linear SDOF systems. The VAMP data was compared to the ideal uni-modal sine pulse as displayed in Fig. 10. The EIS components for the VAMP acceleration pulse are plotted in Fig. 14 with the energy input divided into components of energy dissipated, kinetic energy and energy absorbed for a linear SDOF system with a natural frequency of $15.8 \mathrm{kHz}$.

Figure 13 shows the maximum energy input for the VAMP data is $28.8 \mathrm{Nm} / \mathrm{kg}$ for a linear SDOF system with a natural frequency of $15.8 \mathrm{kHz}$. This correlates well with the signal analysis tools applied in the preceding section where it was shown that the majority of the VAMP signal energy is concentrated between 15.5-18.0 kHz. The uni-modal sine pulse gives a maximum energy of $17.4 \mathrm{Nm} / \mathrm{kg}$ for a linear SDOF system with a natural frequency of $13.7 \mathrm{kHz}$. It is clear that the VAMP data leads to higher energy concentration than the sine pulse. A criterion to compare the input signal response is to measure the frequency bandwidth corresponding to energy values greater than $90 \%$ of the maximum energy, as annotated in Fig. 13. Table 3 displays the energy input data range for the VAMP Ti $-60-120$ pulse and the uni-modal sine pulse acceleration signal.

Table 3 displays an energy input range of $15.0-18.0 \mathrm{kHz}$ over $25.9 \mathrm{Nm} / \mathrm{kg}$ for the VAMP Ti $-60-120$ acceleration signal. The narrow bandwidth is important in relation to practical VAMP applications. It is hypothesised that a VAMP acceleration pulse can be modelled to excite specific components in a multi-component assembly affixed to the VAMP incident test rod.

The absorbed strain energy can be responsible for failure in a micro-device as it represents the energy absorbed by the structure as a result of its structural dynamics, as reported by Smallwood and Edwards [25]. The absorbed strain energy displays a maximum value of $12.4 \mathrm{Nm} / \mathrm{kg}$ at $134.4 \mu \mathrm{s}$, which is $80.0 \mu$ s after the rise-time for the input VAMP acceleration signal. This delay between completing the acceleration signal rise-time and attaining the maximum strain energy is due to the ramp-up of the energy input as the initial kinetic energy is converted and absorbed as 
strain energy by the SDOF system at $15.8 \mathrm{kHz}$. Figure 14 illustrates how the kinetic and absorbed strain energies increase over the first $70 \mu \mathrm{s}$ of the energy input ramp up. The absorbed strain energy levels out between 120-180 $\mu \mathrm{s}$ with two consecutive peaks above $12 \mathrm{Nm} / \mathrm{kg}$. The kinetic and absorbed strain energies then decrease as the signal energy is dissipated as heat and sound with $97.4 \%$ of the total energy dissipated after $500 \mu \mathrm{s}$ in Fig. 14.

The analysis of the energy spectrum illustrated that the maximum energy concentration was at frequencies between $15-18 \mathrm{kHz}$ for the VAMP acceleration excitation. This is because the energy spectrum represents the response of a SDOF spring-mass-damper system and the frequency content of the input pulse is heavily influenced by the incident rod. The incident rod used here was a $120 \mathrm{~mm}$ long, $10 \mathrm{~mm}$ diameter titanium test rod with a first axial resonant mode at $21.5 \mathrm{kHz}$. Thus, varying the parameters of the test rod material and geometry can effectively control the dominant frequency components and hence how the VAMP acceleration signal energy is dissipated.

Analysis of the energy spectrum is useful with a view to critiquing the VAMP as a useful shock tester. It affords insight into how the acceleration pulse is broken down into the relative energy densities and aids in the machine setup to achieve the desired acceleration excitation pulse.

\section{Conclusions}

Experimental shock pulse testing was performed using a VAMP machine and a HPB. The test articles were short cylindrical test rods and acceleration pulses were recorded by an accelerometer on the upper surface of each test rod. Parameters varied were: impact velocity, test rod length, test rod material and contact interface - mitigator use. Statistical sample sets for each test rod were obtained with consistent initial conditions. The VAMP acceleration data range was compared to the HPB data in terms of acceleration magnitude and primary pulse duration with the following conclusions:

- The VAMP was demonstrated as a viable alternative to current shock test methods such as the HPB. It is a novel technique as it applies a small-form factor machine with no external propulsion to generate repeatable controlled shock pulses for a series of initial conditions.

- Isolation of the striker and incident test rods from any complex geometry is a crucial design guideline for the VAMP as it negates the effect of stress wave propagation throughout the penultimate and ultimate masses.

- The acceleration data was low pass filtered at $19 \mathrm{kHz}$ to ensure operation within the linear response region of the accelerometer. For practical VAMP applications, suitable mechanical filtering at $19 \mathrm{kHz}$ is required for the micro-device under test to negate the effect of high frequency components.

- Shock pulses were obtained from the VAMP in excess of 20,000 $\mathrm{g}$ for impact velocities of $5.8 \mathrm{~m} / \mathrm{s}$. It is inferred that much higher shock levels are possible due to the linear relationship between impact velocity and peak acceleration.

- The optimum VAMP configuration was deemed to be the $60 \mathrm{~mm}$ titanium striker and $120 \mathrm{~mm}$ titanium incident rod. This configuration exhibited an acceleration data range of 5,800-23,400 $\mathrm{g}$ and 28.0-44.0 $\mu$ s for impact velocities between $3.5-5.8 \mathrm{~m} / \mathrm{s}$ for flat-flat and mitigator tests.

- Application of plastically deformable mitigators was shown to increase the primary pulse duration at the expense of acceleration magnitude.

- Application of the HWT established a dominant frequency bandwidth of $15.5-18.0 \mathrm{kHz}$ for the VAMP Ti - 60 - 120 configuration and $11.0-12.0 \mathrm{kHz}$ for the $\mathrm{CuBe}-120-120$ configuration acceleration signal.

By comparing the energy spectra for the series of VAMP configurations, it was shown that the spectral content of the acceleration signal can be manipulated through control of the test rod material and length. This is critical in the context of practical VAMP applications, where it is postulated that the VAMP acceleration pulse shape can be controlled to effectively excite specific components in a multi-component assembly affixed to the VAMP incident test rod.

\section{Acknowledgement}

The authors would like to acknowledge the assistance of Prof. Ian (Rick) Hall, Spencer Laboratories, University of Delaware, for his helpful advice and the use of the Hopkinson pressure bar equipment. 
The authors would like to acknowledge the assistance of Mr. David Smallwood and Mr. Tim Edwards, Sandia

Laboratories, for insightful discussions and supplying Matlab code for the signal analysis work.

The authors would like to acknowledge IRCSET (Irish Research Council for Science, Engineering and Technology) for their support of this work. The work is also supported by SFI (Science Foundation Ireland) under grant number 03/CE3/I405.

\section{References}

[1] M. Gad-El-Hak, The MEMS Handbook, New York, CRC Press, 2002.

[2] V.T. Srikar and S.D. Senturia, The reliability of microelectromechanical systems (MEMS) in shock environments, Journal of Microelectromechanical Systems 11(3) (2002), 206-214.

[3] D.J. Frew, M.J. Forrestal and W. Chen, Shock Testing Electrical Components with a Hopkinson Pressure Bar, Society for Experimental Mechanics - 10th International Congress and Exhibition on Experimental and Applied Mechanics, Springfield, MA, 2007.

[4] V.I. Bateman, F.A. Brown and N.T. Davie, Use of a Beryllium Hopkinson Bar to Characterize a Piezoresistive Accelerometer in Shock Environments, Journal of the Institute of Environmental Sciences, 39(6) (1996), 33-39.

[5] W.-Y. Lu, H. Jin, S. Lee, K. Gwinn, W. Chen and B. Song, Dynamic Loading of LIGA Structures, ASME International Mechanical Engineering Congress and Exposition, Chicago, IL., 2006.

[6] B. Rodgers, S. Goyal, G. Kelly and M. Sheehy, The Dynamics of Shock Amplification, International Conference of Mechanical Engineering, London, U.K., 2008.

[7] B. Rodgers, S. Goyal, G. Kelly and M. Sheehy, Dynamics of Shock Amplification through Multiple Impacts, 8th World Congress on Computational Mechanics, Venice, Italy, 2008.

[8] B. Rodgers, S. Goyal, G. Kelly and M. Sheehy, The Dynamics of Multiple Pair-Wise Collisions in a Chain for Designing Optimal Shock Amplifiers, Shock and Vibration 16(1) (2009), 99-116.

[9] G. Kelly, J. Punch, S. Goyal and M. Sheehy, Analysis of Shock Pulses from a Small Velocity Amplifier, Society for Experimental Mechanics - 11th International Congress and Exhibition on Experimental and Applied Mechanics, Orlando, FL., 2008.

[10] G. Kelly, J. Punch, S. Goyal and M. Sheehy, Shock Pulse Shaping in a Small Velocity Amplifier, 79th Shock and Vibration Symposium, Orlando, FL., 2008.

[11] G. Kelly, M. Sheehy, B. Rodgers, J. Punch and S. Goyal, Analysis of High Acceleration Shock Pulses Part I: Geometry of Incident Mass, Society for Experimental Mechanics - 10th International Congress and Exhibition on Experimental and Applied Mechanics, Springfield, MA., 2007.

[12] NASA-STD-7003, Pyroshock Test Criteria, National Aeronautics and Space Administration Technical Standard, 1999.

[13] B. Rogillio and J. Heister, A New Approach to Designing Hopkinson Bar Fly Away Test Fixtures for MEMS Devices, 78th Shock and Vibration Symposium, Philadelphia, PA., 2007.

[14] B.A. Gama, S.L. Lopatnikov and J.W. Gillespie Jr, Hopkinson Bar Experimental Technique: A Critical Review, Applied Mechanics Reviews, 57(1-6) (2004), 223-250.

[15] J.S. Wilson, Shock and Vibration Measurement Technology - An Applications Oriented Short-Course, Endevco Corporation, San Juan Capistrano, CA., 2007.

[16] V.I. Bateman, F.A. Brown and M.A. Nusser, High Shock, High Frequency Characteristics of a Mechanical Isolator for a Piezoresistive Accelerometer, the Endevco 7270AM6, 68th Shock and Vibration Symposium, Albuquerque, New Mexico, 1997.

[17] S.O. Oyadiji, K.T. Feroz and G.R. Tomlinson, Design of Polymer-Based Mechanical Filters for Shock-Measurement Accelerometers, SPIE The International Society for Optical Engineering, Bellingham, WA., 1996.

[18] D.J. Frew, M.J. Forrestal and W. Chen, A Split Hopkinson Pressure Bar Technique to Determine Compressive Stress-Strain Data for Rock Materials, Experimental Mechanics, 41(1) (2001), 40-46.

[19] D.J. Frew, M.J. Forrestal and W. Chen, Pulse Shaping Techniques for Testing Brittle Materials with a Split Hopkinson Pressure Bar, Experimental Mechanics 42(1) (2002), 93-106.

[20] D.J. Frew, M.J. Forrestal and W. Chen, Pulse Shaping Techniques for Testing Elastic-Plastic Materials with a Split Hopkinson Pressure Bar, Experimental Mechanics 45(2) (2005), 186-195.

[21] S. Goyal, J.M. Papadopoulos and P.A. Sullivan, Shock Protection of Portable Electronic Products: Shock Response Spectrum, Damage Boundary Approach, and Beyond, Shock and Vibration 4(3) (1997), 169-191.

[22] ISO/TC-108/SC-N900-Standard, Mechanical Vibration and Shock - Signal Processing - Part 4: Shock Response Spectrum Analysis, 2008.

[23] D. Smallwood, Beyond the Shock Response Spectrum - Short-Course, 78th Shock and Vibration Symposium, Philadelphia, PA., 2007.

[24] D.E. Newland, An Introduction to Random Vibrations, Spectral and Wavelet Analysis, (3rd ed.), New York, Dover Publications, 2005.

[25] D. Smallwood and T. Edwards, Energy Methods for the Characterisation and Simulation of Shock and Vibration - Short-Course, 78th Shock and Vibration Symposium, Philadelphia, PA., 2007.

[26] M. Sheehy, M. Lishchynska, J. Punch, S. Goyal and G. Kelly, The Response of Micro-Scale Devices Subject to High-g Impact Stimuli, Society for Experimental Mechanics - 11th International Congress and Exhibition on Experimental and Applied Mechanics, Orlando, FL., 2008. 

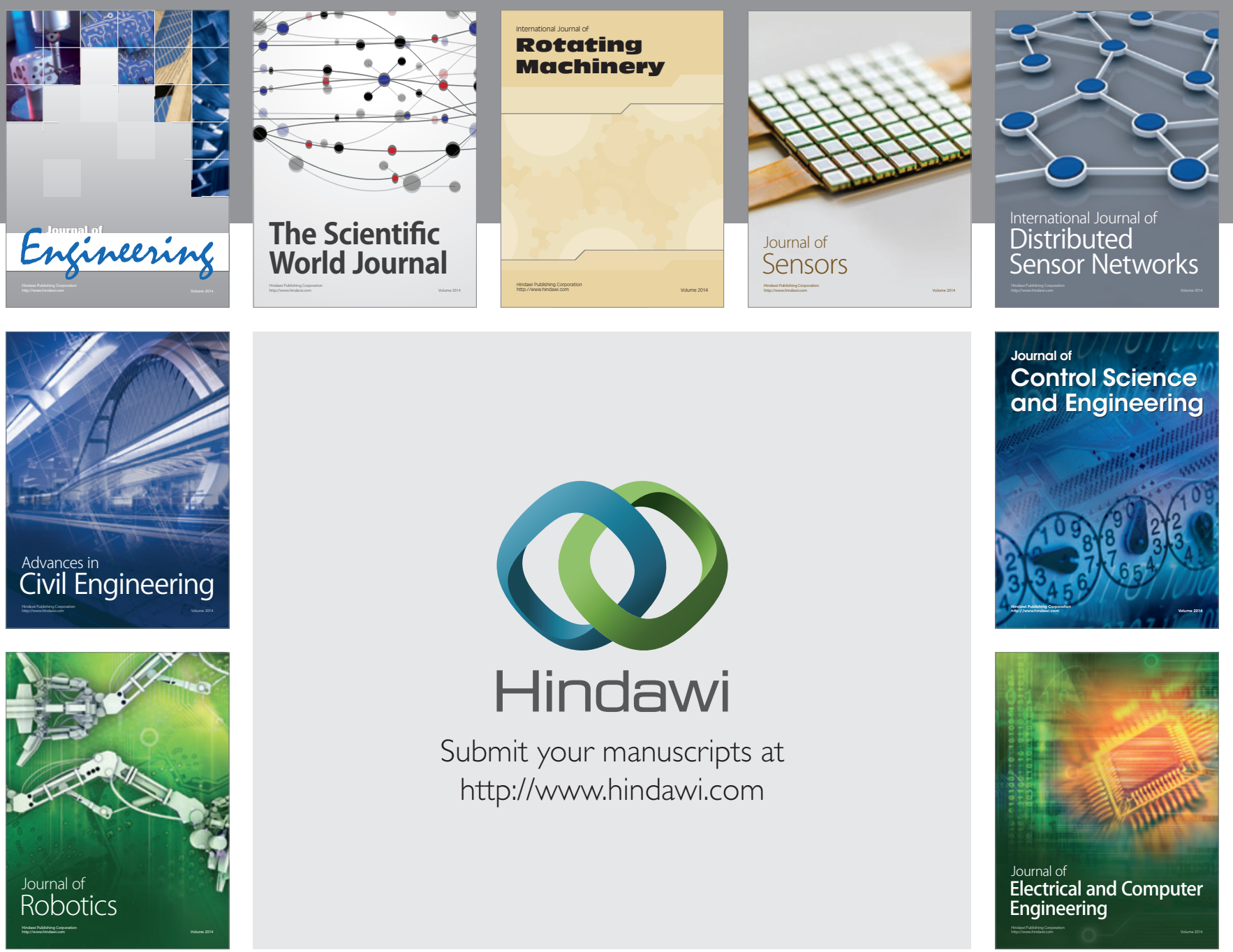

Submit your manuscripts at

http://www.hindawi.com
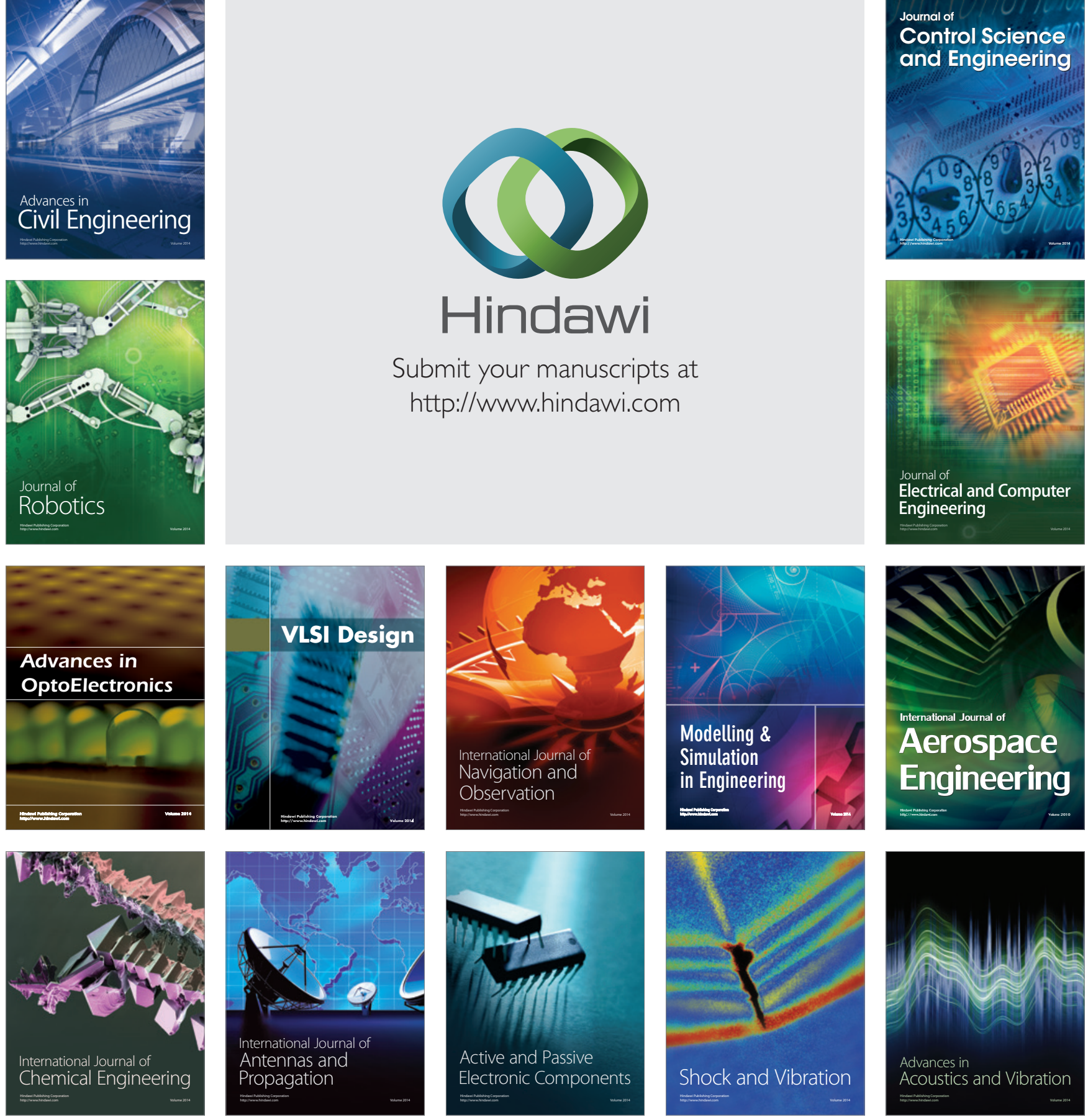